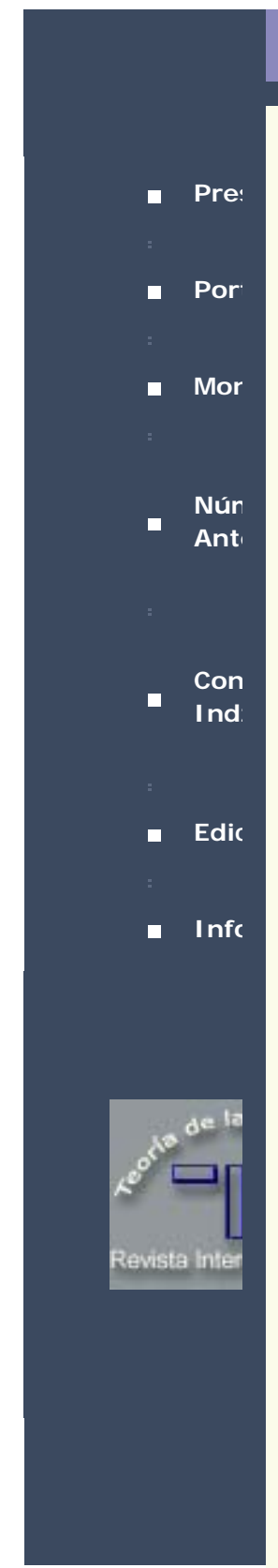

\title{
Educação à distância: elitização ou alternativa de democratizar o ensino?
}

\author{
Ernâni Lampert \\ Universidade Federal Do Rio Grande \\ lampert_ernani@hotmail.com
}

A Segunda Guerra Mundial, que destruiu parte da Europa e cidades da Ásia e afetou a economia, as relações sociais, culturais e políticas do Ocidente e do Oriente, polarizou o mundo em dois blocos. De um lado, o capitalismo, comandado pelos Estados Unidos, e do outro, o socialismo, coordenado pela União das Repúblicas Socialistas Soviéticas. A guerra fria, luta ideológica sem remissão entre as duas grandes potências, redimensionou o mundo, gerando muitas guerras e conflitos desnecessários que destruíram países, mataram e mutilaram milhares de militares e de civis injustamente, deixando outros tantos na pobreza e na miséria.

A competição acirrada entre as duas superpotências deixou a humanidade alerta. As nações, para poderem acompanhar os novos desafios e competir entre si, sem ser dominadas, foram obrigadas a investir pesado no sistema educacional como forma de preparar cientistas, pesquisadores, profissionais, técnicos, enfim, a população em geral.

Havia uma expectativa muito grande em relação à educação e à tecnologia, por isso vários países realizaram reformas educacionais, procurando adequar o sistema obsoleto à nova ordem mundial. Conforme Morin e Kern, "o pós-guerra de 1945 assiste ao renovar das grandes esperanças progressistas. Um excelente porvir é restaurado, seja na idéia do futuro radioso prometido pelo comunismo, seja na idéia do futuro apaziguado e próspero pela sociedade industrial" (1995, p. 80). A educação, que não vinha sofrendo grandes alterações ao longo dos tempos, teve um impulso extraordinário. Novas abordagens, teorias, ensaios, metodologias foram sendo testadas, experimentadas. A formação de professores foi repensada e redimensionada. As universidades começaram a investir em pesquisas e na tecnologia. Foi nesse cenário que foi criada a universidade aberta (Open University) do Reino Unido em 1969, uma reivindicação dos trabalhadores, que serviu e continua sendo referência para o mundo em educação à distância. No que tange à criação dos sistemas de educação superior a distância, Guimarães assim se expressa:

\footnotetext{
Desenhou-se, assim, neste final de século, novas estratégias de políticas educacionais que exigem da parte dos governos e da sociedade a sua formulação concreta e implementação imediata. É nesse contexto que, a partir dos anos 70, surgiram os grandes sistemas nacionais de educação superior a distância, principalmente na Europa e, em seguida, no Canadá, nos Estados Unidos e na Austrália. Mais recentemente, a partir de meados da década de 80, todos os países desenvolvidos criaram os seus sistemas nacionais de educação à distância, o que foi igualmente feito por países em processo de desenvolvimento rápido, como os da Bacia do Pacífico e muitos outros países de menores recursos (1996, p. 29).
}

Atualmente há megauniversidades, instituições de ensino que atendem a mais de cem mil alunos, espalhadas pelos diferentes continentes: China, Indonésia, Índia, Coréia, Tailândia, Turquia, Reino Unido, Espanha, França e África do Sul, que atendem, aproximadamente, a dois milhões e seiscentos mil alunos. Analisando os dados em relação ao número de alunos de cada megauniversidade apresentados por Machado Sousa (1996), observa-se que nos países do Continente Asiático é que se situa o maior contingente destes discentes, talvez por serem países 
mais populosos e apostar na tecnologia como recurso capaz de atender a massa estudantil, que sem essa alternativa não seria possível viabilizar. Sabe-se que as megauniversidades são agências educacionais importantes para o desenvolvimento do país e do continente. Produziram uma revolução no ensino e possibilitaram a um contingente da população acesso à informação, ao ensino e à educação, pois atendem ao mesmo tempo a um grande número de discentes a custo reduzido, o que através da educação convencional seria impossível realizar. A educação à distância foi apontada como uma saída capaz de diminuir as disparidades entre as classes sociais, dando a todos indistintamente a chance de se educarem e ao mesmo tempo ao Estado a possibilidade de reduzir o déficit fiscal, eliminando as despesas com a educação.

Em 1993, os reitores das universidades públicas brasileiras assinaram entre si um convênio do Consórcio Interuniversitário de Educação Continuada e à Distância objetivando a diversificação da oferta das oportunidades educacionais. A implantação do "Brasilead", constituído pelas 54 instituições públicas de ensino superior do país, tem como espaço físico a Universidade Federal de Brasília. Essa iniciativa louvável dos reitores veio em consonância às necessidades da educação permanente e é uma possibilidade de dar oportunidade para milhares de jovens e adultos se atualizarem e se prepararem para o ingresso ou reingresso no mercado de trabalho. Porém, como normalmente a burocratização entrava projetos, há a necessidade de uma série de medidas políticas para viabilizar concretamente essa proposta e beneficiar a população brasileira. Estejamos esperançosos de que essa proposta não seja enterrada antes que produza os benefícios. No parecer de Blois (1996), é imprescindível que o Brasil, se quiser mudar o quadro de atraso em todos os campos, acorde para um novo tempo e utilize a educação à distância ou teleducação, que pode ser através do rádio e da televisão ou através do uso do satélite e das parabólicas de fabricação nacional. O importante é que a educação à distância aconteça logo, sem mais discussões acadêmicas ou políticas, para que a educação seja democratizada, pois a sociedade brasileira já amadureceu o suficiente para entender que estruturas formais não conseguirão atender às demandas exigidas no campo da educação. Marchessou (1997) assinala que os países que desejam passar do terceiro mundo para o desenvolvimento, utilizam, com freqüência, o ensino à distância como remédio possível para atender as carências educativas, enquanto os países desenvolvidos lançam mão do ensino aberto e à distância para dar resposta às necessidades de educação permanente das populações altamente diversificadas em seus conhecimentos, aspirações e expectativas, tornando assim acessíveis a todos as novas descobertas fora dos espaços restritos que são as instituições escolares e universitárias.

Inúmeros são os autores nacionais e internacionais que têm definido a educação à distância. Mesmo assim, o termo com muita freqüência tem sido utilizado de forma errônea. García Aretio, em seu trabalho "Para uma definição de educação à distância" (1987), apresenta inúmeras definições de autores internacionais e, após análise, definiu a educação à distância como sendo “...um sistema tecnológico de comunicação de massa e bidirecional, que substitui a interação pessoal, em aula, de professor e aluno, como meio preferencial de ensino, pela ação sistemática e conjunta de diversos recursos didáticos e o apoio de uma organização tutorial, que propiciam a aprendizagem autônoma dos estudantes" (p. 60). Perraton, referenciado pela Unesco, (1997) descreve a educação à distância como "um processo educacional em que uma proporção significativa do ensino é conduzida por alguém distante em tempo e/ou espaço do aprendizado" (1997, p. 25). A educação à distância é uma organização de ensino-aprendizagem individualizada, que tem objetivos, metodologias e sistemas de avaliação definidos e, apoiando-se em uma variada gama de recursos tecnológicos (material impresso, correspondência escrita, áudio, vídeo e mídia e redes baseadas no computador), sem o contato formal de professor e aluno, objetivando democratizar a educação, propiciando sem distinção de idade, raça, credo religioso, ideologia política ou classe social, a oportunidade de completar escolaridade, reciclar e/ou atualizar-se para enfrentar os desafios do cotidiano.

A educação à distância não é uma proposta alternativa do século XX. A comunicação com objetivo de gerar aprendizagem em indivíduos fisicamente distantes teve suas origens na Idade Clássica, com os gregos e romanos, e acompanhou a humanidade ao longo de sua história. No Brasil, certamente o passo inicial foi dado por Roquette-Pinto, na década de 20, com a criação da Rádio Sociedade do Rio de Janeiro e um plano de utilização da radiodifusão para ampliar o acesso à educação. Saraiva (1996), em seu artigo "Educação à distância no Brasil: lições da história", apresenta uma relação de experiências e de trabalhos desenvolvidos de ensino à distância realizados por empresas, escolas e universidades ao longo do século XX, que poderá servir de aporte para o leitor desejoso em 
aprofundar essa temática. Em síntese, pode-se concluir que "vivemos a etapa do ensino por correspondência; passamos pela transmissão radiofônica e, depois, televisiva; utilizamos a informática até os atuais processos de utilização conjugada de meios - a telemática e a multimídia" (Saraiva, 1996, p. 19). Garcia (1997) assinala que no Brasil a educação à distância tem uma história que não pode ser ignorada, pois ao longo dos anos houve organizações privadas que forneceram cursos à distância a milhões de brasileiros, numa época em que não existiam comunicações mais modernas e em boa parte do território nacional as únicas informações chegavam via correio. Os cursos por correspondência têm uma tradição que não pode ser desconhecida e muito menos desprezada.

Castro Neves (1996), referindo-se às razões que justificam a significativa expansão da educação à distância, assinala que, onde os recursos são escassos, ela amplia as oportunidades, permitindo uma educação mais eqüitativa; familiariza o cidadão com as tecnologias que estão no seu cotidiano, além de oferecer meios de atualizar rapidamente o conhecimento técnico. Segundo a autora, a incorporação da metodologia da educação à distância no cotidiano escolar representa uma estratégia para dinamizar o ensino, elevar sua qualidade e instrumentalizar professores e alunos, desenvolvendo neles atitudes autônomas e críticas, indispensáveis. Portanto, é oferecer a todo o cidadão uma educação que prepare à autonomia, à inovação, à criatividade, à aprendizagem contínua, para o desenvolvimento científico e tecnológico, para a redução das desigualdades sociais e para o desenvolvimento de valores humanos, éticos e sociais. Para Blois (1996), o que há de mais fantástico na educação à distância é que ela acompanha o progresso tecnológico, incorporando novos meios que são colocados a serviço da educação, e que esta modalidade de ensino nãopresencial rompe com os preceitos até então considerados indispensáveis para que a aprendizagem se realizasse: - a presença física de quem ensina e dos que aprendem; - espaço físico definido e específico (sala de aula); - estrutura organizacional básica (escola); - turmas com grupo de alunos o mais homogêneo possível; - discurso oral como meio de passar mensagens; - tempo de aprendizagem imposto (ano letivo, carga horária). Guimarães (1996) registra que o rápido desenvolvimento dos sistemas nacionais de ensino à distância fez sobressair três ordens de diferença em relação ao ensino presencial, a saber:

- metodologia do ensino. $\mathrm{O}$ ensino à distância se baseia no princípio de auto-aprendizagem. $\mathrm{O}$ estudante, dispondo dos recursos adequados, conforme sua predisposição, ritmo de aprendizagem, motivação, efetivará a aprendizagem em locais por ele determinados. A avaliação, por sua vez, é formal e presencial,

- estrutura organizacional. O sistema de ensino à distância necessita de pelo menos um centro de produção de materiais de instrução: editorial, estúdio de produção de vídeo e áudio, centro de produção de software. É importante que haja redes organizadas de distribuição desses materiais (postal, emissoras de rádio e TV, rede de microcomputadores). Para o sucesso desse empreendimento, o pessoal administrativo precisa ser treinado, pois toda a interação com os estudantes é feita à distância: registro de inscrição, publicação de resultados, pagamentos, informações com notas, etc. A informatização da instituição é indispensável. O pessoal docente é reduzido, porque a comunicação docente/discente não é sistemática;

- ordem econômica. O uso de tecnologia de produção e difusão de informação exige investimento de capital, mas permite reduzir as necessidades de pessoal docente. Há de ser considerado que os custos de produção de materiais de aprendizagem são geralmente elevados e variam de país para país.

Quanto aos meios utilizados no ensino à distância, Yalli (1995) arrola os textos impressos, o rádio, a televisão, o computador e o telefone como os principais. O texto impresso permite que o aluno aprenda conforme as suas possibilidades, dedicação e condições. A relação docente/discente será consolidada pelo correio ou algum meio equivalente. O êxito desse meio dependerá da adequação dos objetivos didáticos às possibilidades do texto; da habilidade expressiva por parte do autor do texto, unida à planificação, à seqüenciação e à adaptação das mensagens às características do discente; da habilidade de leitura e capacidade de assimilação dos conteúdos por parte do aluno, e da tutoria disponível ao aluno. O rádio é um autêntico meio de comunicação de massa, por sua versatilidade. Diminui a sensação de solidão em relação ao texto impresso. A comunicação entre docente e discente é unidirecional. Por isso há a necessidade de que o professor, através da voz, 
desperte a motivação dos alunos à aprendizagem. A utilização do rádio como meio permite a consecução dos objetivos de compreensão e expressão oral; a repetição dos programas emitidos; a diminuição da solidão do estudante; a economia na produção e transmissão imediata das mensagens. A televisão, autêntico meio de comunicação de massa, que une o som e imagem, tem se relevado como um meio frio de comunicação de mensagens. Tem sido usado em campanhas maciças de alfabetização, no ensino profissionalizante, na atualização profissional e emprego de complementação de escolaridade obrigatória. A utilização da televisão para fins instrutivos está no seu potencial por ser o meio mais completo para a transmissão de conteúdos, fazendo do ensino uma atividade viva e interessante. Esse meio implica necesssariamente o apoio de outros recursos, como materiais impressos, por exemplo. O computador, largamente utilizado nas classes sociais média e alta, tem a desvantagem de ser um equipamento caro, o que praticamente inviabiliza o acesso da camada popular. Porém, no plano pedagógico, tem mostrado resultados favoráveis, pois atende às peculiaridades dos discentes. O telefone tem uma função mais tutorial do que de docência. Permite ao professor e ao aluno um intercâmbio. Seu uso é recomendado em todo o sistema de ensino à distância, como elemento auxiliar ou de reforço. Villegas Grijalba (1989), em seu trabalho, que resultou do exercício da docência na Universidade Nacional de Educação à Distância, da Costa Rica, durante mais de onze anos de trabalho ininterrupto, fornece aspectos relevantes da tutoria telefônica. Segundo o autor, apesar dos esforços no sentido de capacitar os tutores, persiste a ausência de um modelo didático com um referencial teórico para esse tipo de serviço. Cevo, citado por Villegas Grijalba, diz que a cordialidade, o estabelecimento de um nexo de confiança, a clareza na expressão e o perfeito domínio do conteúdo são alguns requisitos que o funcionário que cumpre essa função necessita ter. Gonzáles e outros, também citados por Villegas Grijalba, apresentam vantagens e desvantagens da tutoria telefônica. Entre as desvantagens, a existência de somente uma linha, o que congestiona nos momentos de "pico"; os estudantes da zona rural muitas vezes não dispõem de telefones; os alunos não têm suficiente clareza na elaboração das perguntas; a voz do tutor não parece traduzir um bom serviço, e alguns conceitos são difíceis de serem explicados por telefone. Villegas Grijalba também observa que em mais do que $75 \%$ do tempo o serviço de tutoria telefônica não é utilizado. A consulta recai nos dias imediatamente anteriores à entrega dos instrumentos de avaliação. Moore (1989) enfatiza que há várias razões para usar os meios nãoimpressos, pois alguns são instrucionalmente mais fortes, permitindo ao estudante mais controle sobre seu material de aprendizagem, e também oferecem melhores formas de retroalimentação. Dentre esses meios mais comuns estão o rádio, a televisão, o satélite, o áudio e o videocassete, conferências por telefone, computadores, microcomputadores, teletextos e videodiscos. O videocassete possibilita o estudante aumentar o poder de controle do estudo. $\mathrm{O}$ aluno pode ver o programa com freqüência, com pausas e repetições. As conferências por telefone permitem o estudante se aproximar de seu instrutor e vice-versa, possibilitando interação entre eles. As videoconferências representam um campo atrativo para completar os recursos utilizados na educação à distância, pois permite a comunicação audiovisual espontânea.

Maia (1998), em estudo crítico de alguns aspectos essenciais no ensino à distância - a tutoria e a avaliação - alerta que o ensino à distância não pode ser considerado como um método, mas um sistema em que objetivos, meios, técnicas e material resultem de uma filosofia, uma concepção de ensino. Assim, todos os componentes deverão funcionar harmoniosamente. Quanto à tutoria, muitas universidades mantêm esse subsistema, porém com o intuito administrativo, ou seja, distribuição de material. Para a autora, é requisito fazer da tutoria uma presença, um apoio, um auxílio para o aluno, onde, em horários rigorosamente estabelecidos, obtenha respostas às consultas através de entrevistas, contato telefônico, fax, e-mail, etc. A avaliação é outro subsistema que merece ser analisado. Qual ou quais as formas e instrumentos de avaliação que serão utilizados? A forma reprodutora, reconhecedora, adaptadora e funcional tem funções claras e implicações ideológicas, como também os instrumentos de auto-avaliação, trabalhos individuais de pesquisa, provas presenciais, a monografia final, etc. A tutoria e a avaliação não podem ser consideradas isoladamente. Constituem-se em subsistemas interativos. No funcionamento do sistema, eles devem ser ontologicamente interligados, realimentando-se e realimentando o sistema. Ibarra Sáiz, Gil Flores e Rodríguez Gómez (1994) concluíram em pesquisa realizada com 2803 alunos de diferentes cursos acadêmicos de 1991-1992 da Universidade Nacional de Educação à Distância da Espanha que, em termos gerais, os dois principais campos de melhoria assinalados pelos discentes são a relação professor/aluno e o sistema de avaliação. Os alunos reivindicam claramente um contato pessoal, que pode ser incrementado com a convivência da tutoria. O sistema de avaliação merece uma revisão de alguns conteúdos e de alguns materiais didáticos empregados. Para Fancholo 
(1997), as ações de tutoria facilitam a aprendizagem do estudante através do diálogo intersubjetivo, hoje cada vez mais meado pelos artefatos tecnológicos. Trata-se de um processo de comunicação em um continuum que vai desde os mais distantes aos mais próximos, a cara-a-cara. As funções básicas da tutoria são: - orientação didática em conteúdo, administrativa e favorecimento de hábitos de estudo; - a avaliação, correção de trabalhos práticos de campo; - aconselhamento e assessoria acadêmica, de bibliografia e melhoramento de aprendizagem e suporte motivacional. Letwin (1999) registra que, nos anos 90, a incorporação de redes de satélite, o correio eletrônico, a utilização da Internet e os programas especialmente planejados para os suportes informáticos são os grandes desafios da educação à distância, e que por sua vez podem resolver um problema crucial - a interatividade, pois os avanços das comunicações eletrônicas permitem aos usuários consultar os especialistas, trocar opiniões, problemas ou propostas com outros usuários.

Diaz Bordenave (1988), em seu estudo que questiona se a educação à distância pode ajudar a resolver os problemas educacionais do Brasil, apresenta vantagens, desvantagens, perspectivas e desafios dessa modalidade de ensino. Quanto às vantagens, o autor enumera que a educação à distância pode alcançar um grande número de pessoas e grupos, mesmo que as distâncias físicas e sociais entre os indivíduos sejam enormes; facilita a aprendizagem das pessoas, permitindo o uso do tempo disponível, sem a necessidade de se locomoverem do lar ou do local de trabalho; adapta-se ao ritmo próprio de aprendizagem de cada indivíduo, podendo ser realizada em grupos ou individualmente; reduz o custo de capacitação por estudante, além de economizar com as despesas pessoais (transporte, alojamento, alimentação, etc.) do aluno; requer poucos instrumentos para elaborar os conteúdos e materiais didáticos, permitindo, assim, a contratação dos melhores especialistas em cada área do conhecimento; serve, pela versatilidade da metodologia, tanto à educação formal quanto à informal; utiliza uma infinidade de recursos tecnológicos; desenvolve a capacidade do autodidatismo, isto é, de aprender por si, sem a presença de um professor. Em relação às desvantagens, Diaz Bordenave aponta a alta taxa de evasão; a desconfiança das pessoas por um sistema de ensino sem a presença física do professor; a unificação dos cursos, sem levar em consideração a diversificação e descentralização dos conteúdos; desatualização freqüente dos materiais didáticos e dos conteúdos propriamente ditos; a passividade no processo e a impossibilidade de controlar vários fatores (aparelhos estragam na hora dos programas, etc.).

Portanto, a educação à distância, que apresenta grandes vantagens e severas limitações, que precisam ser avaliadas, analisadas e redimensionadas para o êxito dessa importante e atualizada modalidade de ensino-aprendizagem, é capaz de aumentar as possibilidades de estudos da população brasileira.

De acordo com Guadamuz (1997), o ensino à distância conseguirá superar os desafios na medida em que: seja assegurado que o contexto da educação permanente é um componente essencial do sistema educativo; que é um conjunto sistêmico que gera economias de escala importante para o estado; que o estado faça investimentos em particular nos dispositivos tecnológicos e na reengenharia dos produtos; que corresponda às necessidades e às situações de vida de milhões de usuários do sistema educativo e do sistema produtivo; que a natureza dessa modalidade de ensino esteja vinculada ao desenvolvimento das tecnologias da informação e da telecomunicação; que as instituições públicas de ensino à distância incorporem os enfoques novos do aparato tecnológico para ficar no contexto dos intercâmbios de conhecimentos mundializados; - que as instituições colaborem e se associem para encontrar respostas às novas demandas tecnológicas; que o ensino à distância fique acessível material e economicamente ao conjunto dos cidadãos; que as instituições possam transformar sua cultura organizacional em função dos objetivos que as mudanças apresentem; que as instituições realizem pesquisas. Para o autor, no futuro, o ensino à distância terá como características: a descentralização; será interativo e individualizado; será adaptado a diferentes estilos de aprendizagem; será operado pela multimídia, de forma a estimular os vários sentidos; facilitará o acesso à informação por um enfoque em hipertexto; será acessível nas casas, nos centros específicos de capacitação e no local de trabalho; utilizará as redes de telecomunicação; será acompanhado de uma avaliação contínua e integral e apoiado pelo desenvolvimento de software de formação automatizada e suporte de sistemas inteligentes.

A educação à distância perpassou distintos períodos históricos e está galgando posição de destaque na sociedade hodierna. Certamente será o sistema de ensino do século XXI, tanto nos países desenvolvidos quanto nos emergentes. Os elevados déficits públicos em praticamente todos os 
países requerem cortes nos investimentos e redução nas despesas, o que implica cortes de pessoal e de material, enquanto a população principalmente nos países emergentes continua crescendo. A educação à distância é apontada como uma via capaz de atender uma demanda cada vez mais crescente da população à procura de educação básica, superior e profissional e de cursos de atualização. Por outro lado, há uma preocupação generalizada com o futuro do Estado, ou seja, da impossibilidade de atender os serviços sociais essenciais: educação, saúde e previdência, indispensáveis à convivência salutar e produtiva da população. Assim, através do emprego maciço da tecnologia, os governos têm buscado caminhos para fazer frente às necessidades básicas das pessoas, ao mesmo tempo em que realizam experiências com o intuito de obter soluções para os desafios cada vez maiores e mais constantes, num mundo em que as mutações são velozes e apresentam complexidade e contradições. Além desse aspecto econômico, é mister considerar que parcela significativa da população mundial está desempregada, necessitando com premência se reciclar para ter alguma possibilidade a mais de reingressar no mercado de trabalho praticamente saturado em todas as áreas do conhecimento e que exige recursos humanos criativos, atualizados com as novas tecnologias de ponta. A educação à distância é um recurso que, de imediato, a curto prazo e a custo reduzido, é capaz de reciclar esses indivíduos à beira da exclusão e reintegrá-los como agentes produtivos num sistema competitivo.

Hoje em dia, principalmente nos países emergentes, a educação convencional não consegue atender quantitativa e qualitativamente. Por exemplo, no Brasil, o sistema educacional convencional está excluindo cada vez maior número de indivíduos por apresentar uma metodologia de ensino arcaica, conteúdos defasados, professores muitas vezes despreparados. A educação convencional objetiva preparar tanto a instrução básica quanto superior de jovens e adultos para um mercado de trabalho que já não existe mais e sem perspectiva imediata de aquecimento. Há quase unanimidade entre os estudantes quanto ao tipo de ensino prestado pelos agentes convencionais, ou seja, teórico, abstrato, elitizante, dissociado da realidade, desarticulado, que não condiz com a realidade. Diante disso, realidade, vale a pena ficar investindo os escassos recursos na educação tradicional ou tentar rever essa caótica qualidade de ensino? Outro aspecto importante que merece análise é que a educação à distância pode servir para complementar a convencional ou vice-versa, sem o objetivo de competir ou concorrer, mas uma ser complemento da outra, preenchendo hiatos de formação ou propiciando novas leituras, modos de pensar, encarar a vida. A complementaridade beneficiará ambos os sistemas de ensino, além de possibilitar ao estudante a possibilidade de escolher. "La educación a distancia ha demostrado ser el complemento ideal de la educación presencial, ya que ha permitido llevar la educación a grandes masas, que de otra manera no hubieram podido alcanzarla" (Yee Seuret e Miranda Justiniani, 1995, p. 28). Sabe-se que a educação à distância tem acompanhado mais agilmente as mudanças do que a escola tradicional, pois incorpora as novas tecnologias ao sistema, possibilitando aos alunos uma aproximação maior com o cotidiano, ao mesmo tempo em que a aprendizagem se torna mais dinâmica e interessante. "La metodología de la educación abierta y a distancia, por el contrario, ha demostrado su potencialidad de crecimento y consolidación debido precisamente a la flexibilidad para incorporar, experimentar y evaluar nuevas formas de aprendizage del conocimiento" (Pontes Gonzáles e Barrón Soto, 1996, p. 9).

A educação à distância, que poderá atender a grandes distâncias no Brasil, é uma alternativa viável de que o governo poderá lançar mão para atenuar as gritantes diferenças regionais, propiciando à população do norte e nordeste as condições mínimas de escolaridade indispensáveis para melhor conviver com as péssimas condições de vida que são impostas. Em relação a esse assunto, Luckesi diz que "... o ensino à distância manifesta-se como uma alternativa de mediação na construção de uma sociedade culta, crítica e civilizada" (1989, p. 11). É imprescindível apostar-se na educação à distância não como única maneira de recuperar o atraso, mas como uma via capaz de rever o caos brasileiro. A educação à distância não é uma panacéia que irá equacionar todos os problemas educacionais, mas é com certeza uma perspectiva viável a ser levada a cabo, experimentando, refletindo e redimensionando a educação. Para obter os resultados desejados, necessita de investimentos altos, especificamente quando da implantação dos programas. É condição indispensável para o êxito a contratação de recursos altamente qualificados nessa modalidade de ensino, em conteúdos e tecnologia. Por exemplo, a Open University contrata os melhores professores da Gran Bretanha, o que lhe conferiu credibilidade.

Para o êxito dos programas de educação à distância, há a necessidade de se constituírem pelo menos três núcleos: pedagógico, telecomunicação e administrativo/ financeiro. O pedagógico é responsável 
pela organização e planejamento dos cursos, programas, conteúdos, metodologia de ensino, sistema de avaliação, bibliografia, tutoria, etc. O bom funcionamento desse núcleo é de vital importância para o andamento harmonioso desse sistema de educação. Há a necessidade de haver no sistema de avaliação a especificação dos instrumentos e critérios de forma clara, o que confere ao curso maior confiabilidade. Os instrumentos devem ser selecionados, treinados, atendendo os requisitos exigidos para cada curso. O núcleo de telecomunicações também exerce um papel importante nesse sistema educativo. É responsável pelos recursos tecnológicos a serem utilizados nos programas, cursos, etc. Os técnicos precisam ter preparo e treinamento específico nos diversos recursos: rádio, televisão, material impresso, computador, vídeo, Internet, etc. O núcleo administrativo e financeiro deve servir de apoio aos demais e dar sustentação ao sistema. Os preços dos cursos fixados por núcleo devem levar em consideração os empenhos, porém os preços devem ser acessíveis para democratizar o ensino.

A educação à distância, ao longo de sua trajetória, tem alcançado resultados favoráveis tanto em países industrializados quanto nos emergentes em diferentes áreas: alfabetização e educação de adultos, cursos de atualização e de reciclagem, cursos profissionais, treinamento em serviços, educação básica, superior, ensino de pós-graduação: especialização, mestrado e doutorado e qualificação de professores. Quanto a essa situação, Todorou (1994) diz que a experiência mundial vem mostrando que o ensino à distância é um grande potencial para o desenvolvimento de programas de capacitação e qualificação de professores. No Brasil há diversas experiências pontuais nesse sentido e os resultados atingidos tem colaborado na melhoria da qualidade do ensino. Entretanto, há de ser registrado que os docentes, com exceções, apresentam resistência em relação a qualquer inovação ou uso da tecnologia educacional. Analisando os problemas da incorporação de tecnologias educacionais modernas nos países em desenvolvimento, Poppovic (1996) diz que

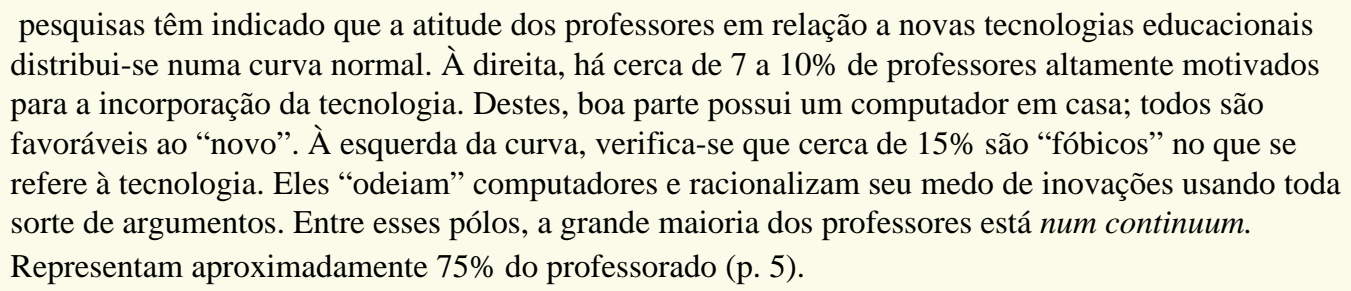

Essa citação deixa clara a resistência do professorado. E para que a incorporação de tecnologia educacional tenha êxito, é indispensável primeiramente "alfabetizar em informática" os docentes. Esse processo, ainda que despenda tempo e muitos recursos, será condição, pois sem esse preparo será inútil equipar as escolas com computadores, televisão, parabólicas. Os professores são receosos de que a tecnologia venha a substituí-los, mas na realidade apenas mudará a atuação do professor e do aluno. No parecer de Demo (1998), não adianta resistir, pois as mudanças oriundas da informática não são opcionais no sentido de poderem ser apagadas da história. Já são fato consumado e crescente. É preciso jogar o jogo como ator, sujeito capaz.

Demo (1998) analisa criticamente a teleducação, levantando algumas questões em relação a essa modalidade de ensino. Segundo ele, as avaliações têm mostrado que os programas de teleducação podem facilmente tornar-se mais atraentes, mais bem montadas tecnicamente, incluindo a computação gráfica, desenhos animados, interatividade, mas a aprendizagem dos alunos continua muito pouco significativa, inferior se os resultados são comparados com a escola convencional. A teleducação é de extrema utilidade para processos educativos, porém tende a ser apenas ensino. A distância, por si, não educa nada nem tem nada de educativo. Entretanto, ela pode facilitar a vida dos alunos. O mesmo acontece com a intrumentalização eletrônica, que por si também não é educativa ou formativa. A teleducação está marcada por facilidades duvidosas, que nem sempre correspondem a aprendizagem autêntica. As críticas de Demo são procedentes e merecem reflexão. A própria Lei 9394/96 - Lei de Diretrizes e Bases da Educação Brasileira confunde ao longo do texto os termos educação e ensino, quando se refere a educação à distância. O imperativo deste estudo não é analisar essa polêmica, porque há inúmeros achados que estudam essa problemática e parece não ser o ponto crucial. Intenciona-se discutir a educação à distância, oferecendo ao leitor uma visão da organização, do funcionamento, da metodologia, das vantagens, desvantagens, desafios e perspectivas desse sistema educativo e apontá-lo como uma alternativa de democratizar o ensino. Reconhece-se que o sistema funciona bem em países do Primeiro Mundo, onde a cultura 
valoriza essa modalidade, o que certamente não ocorre com a população em geral de países em via de desenvolvimento.

Sabe-se que a educação à distância tem um caminho enorme a percorrer e deve encontrar com urgência saídas para os desafios que realmente apresenta. Para Costa, Fagundes e Nevado (1998), a educação à distância se constitui numa mudança, numa nova realização do fazer educativo que contempla novos processos, produtos e serviços. Necessita de investigação para ser melhor conhecida e melhorada e , também, existe a necessidade de investigar para elaborar, consolidar ou modificar o campo teórico que sustenta essa modalidade de ensino. Segundo Marín Ibáñez (1998), a educação à distância é uma das tendências mais vigorosas e inovadoras para o século XXI. Ela responde aos ideais de igualdade de oportunidades, de educação permanente e às exigências de uma economia de escala, superando os limites tempo/espaço e restrições econômicas. Pode responder, por um lado, a uma demanda global, já inevitável e por outro, a uma adaptação aos interesses e as circunstâncias pessoais. Cada um estudo aproveitando qualquer tempo e lugar propício.

\section{Bibliografía.}

BLOIS, M. M. "Educação à distância via rádio e TV educativas : questionamentos e inquietações". Em Aberto, v. 16, n. 70, p. 42-50, abr.-jun. 1996.

CASTRO NEVES, C. M. "O desafio contemporâneo da educação à distância". Em Aberto, Brasília, v. 16, n. 70, p. 34-41, abr.-jun. 1996.

COSTA, I. E. T., FAGUNDES, L. C., NEVADA, R. A . "Projeto TEC-LEC": modelo de nova metodologia em EAD incorporando os recursos da telemática. Informática na educação : teoria \& prática, Porto Alegre, v. 1, n. 1, p. 83-100, out. 1998.

DEMO, P. Questões para a teleducação. Petrópolis : Vozes, 1998.

DIAZ BORDENAVE, J. E. "Pode a educação à distância ajudar a resolver os problemas educacionais do Brasil?" Tecnologia Educacional, Rio de Janeiro, n. 80-81, p. 31-36, jan.-abr. 1988.

FANCHOLO, B. "La tutoría en la educación a distáncia : problemas y recomendaciones". Tecnologia Educacional, Rio de Janeiro, v. 25, n. 136-137, p. 39-41, mar.-jun.-jul.-ago. 1997.

GARCIA ARETIO, L. "Para uma definição de educação à distância". Tecnologia Educacional, Rio de Janeiro, v. 16, n. 78-79, n. 56-61, set.-dez. 1987.

GARCIA, W. E. "Educação à distância : desafios na virada do século : notas para debate".

Tecnologia Educacional, Rio de Janeiro, v. 26, n. 142, p. jul.-ago.-set. 1998.

. Legislação, políticas públicas e gestão para o ensino à distância. Tecnologia Educacional, Rio de Janeiro, v. 25, n. 139, p. 16-18, nov.-dez. 1997.

GUADAMUZ, L. "Tecnologias interativas no ensino à distância". Tecnologia Educacional, Rio de Janeiro, v. 25, n. 139, p. 27-31, nov.-dez. 1997.

GUIMARÃES, P. V. "A contribuição do consórcio interuniversitário de educação continuada e à distância - Brasilead - para o desenvolvimento da educação nacional". Em Aberto, v. 16, n. 70, p. 28 -33, abr.-jun. 1996.

IBARRA SAIZ, M. S., GIL FLORES, J., RODRÍGUEZ GÓMEZ, G. "Elementos para la mejora de la educación superior a distancia". Revista Iberoamericana de educación supoerior a distancia, Madri, v. 6, n. 3, p. 19-37, 1994.

LETWIN, E. "Desafios, recursos e perspectivas da educação à distância". Pátio, Porto Alegre, v. 3, n. 9, p.16-19, maio-jun. 1999.

LIGUORI, L. M. As novas tecnologias da informação e da comunicação no campo dos velhos 
problemas e desafios eduucacionais. In: LITWIN, E. Tecnologia educativa: política, histórias e propostas. Porto Alegre: Artes Médicas, 1997.

LION, C.G. Mitos e realidade na tecnologia educacional. In: LITWIN, E. Tecnologia educacional: política, histórias e propostas. Porto Alegre: Artes Médicas, 1997.

LUCKESI, C. C. Democratização da educação : ensino à distância. Tecnologia Educacional. Rio de Janeiro, v. 18, n. 89-90-91, p. 9-12, jul.-dez. 1989.

MACHADO SOUSA, E. C. B. "Panorama internacional da educação à distância". Em Aberto, Brasília, v. 16, n. 70, p. 9-16, abr.-jun. 1996.

MAIA, N. A. "A tutoria e a avaliação - duas questões críticas no ensino à distância". Ensaio : avaliação e políticas públicas em educação. Rio de Janeiro, v. 6, n. 21, p. 463-474, out.-dez. 1998.

MARÇAL, J. C. "Ensino à distância : das críticas a um novo fazer educativo". Pátio, Porto Alegre, v. 3, n. 9, p. 49-58, maio-jul. 1999.

MARCHESSOU, F. Estratégias, contextos, instrumentos, fórmulas : contribuição da tecnologia educativa ao ensino aberto e à distância. Tecnologia Educacional, Rio de Janeiro, v. 25, n. 139, p. 615, nov.-dez. 1997.

MARÍN IBANEZ, R. La educación del siglo XXI: Hacia un sistema tecnológico multimedia. Las universidades a distancia. Educación XXI, Madrid, Universidad Nacional de Educación a distância, 1998.

MENEZES, C. "Experiências de educação à distância na América Latina". Tecnologia Educacional, Rio de Janeiro, v. 26, n. 140, p. 37-40, fev.-mar. 1998.

MÖHLE, H. "The further development of Adult Distance Education". Educación y Sociedad, v. 2, n. 2, p. 61-71, jun.-dez. 1991.

MOORE, M. G. "Universidade à distância para educação de adultos". Correio de Belamira, Pojuca, v. 10, n. 25, p. 6-9, jan.-jun. 1989.

MORIN, E., KERN, A B. Terra-Pátria. Porto Alegre : Sulina, 1995.

NISKIER, A. Mais perto da educação à distância. Em Aberto, v. 16, n.70, p. 51-56, abr.-jun. 1996.

PONTES GONZALES, E., BARRÓN SOTO, H. Contribución de los nuevas tecnologías para el futuro de la educación superior a distancia. Revista Iberoamercicana de educación superior a distancia, Madrid, v. 8, n. 2, p. 7-13, nov. 1996.

POPPOVIC, P. P. "Educação à distância : problemas da incorporação de tecnologias educacionais modernas nos países em desenvolvimento". Em Aberto, Brasília, v. 16, n. 70, p. 5-8, abr.-jun. 1996.

SARAIVA, T. "Educação à distância no Brasil : lições da história". Em Aberto, Brasília, v. 16, n. 70, p. 17-27, abr.-jun. 1996.

TODOROU, J. C. "Qualidade para a educação". Revista Brasileira de Educação à Distância, Rio de Janeiro, v. 1, n. 2, p. 9-11, jan.-fev. 1994.

UNESCO. Aprendizagem aberta e à distância : perspectivas e considerações sobre políticas educacionais. Florianópolis : Universidade Federal de Santa Catarina, 1997.

VILLEGAS GRIJALDO, J. J. "Sínteses diacrónica del sistema tutorial de la universidad estatal a distancia de Costa Rica". La Educación, Washington, v. 33, n. 105, p. 39-55, 1989. 
YALLI, J. S. "Educação à distância". Tecnologia Educacional, Rio de Janeiro, v. 22, n. 123-124, p. 37-41, mar.-jun. 1995.

YEE SEURET, M., MIRANDA JUSTINIANI, A. "La educación a distancia como factor de integración iberoamericana". Revista Iberoamaericana de Educación Superior a Distancia. Madrid, v. 7, n. 3, p. 27-32, 1995.

(C) Ediciones Universidad de Salamanca.

Páginas mantenidas por Francisco Ignacio Revuelta Domínguez

y Luis González Rodero

webmrte@usal.es 